\title{
Analysis of a comprehensive wellness program's impact on job satisfaction in the workplace
}

\author{
Craig Marshall \\ School of Hospitality Leadership, East Carolina University, Greenville, \\ North Carolina, USA
}

\begin{abstract}
Purpose - This research study included an examination into the extent that a comprehensive wellness program affects employees' job satisfaction levels. As the leaders of more hospitality organizations implement wellness programs in the workplace, they will want to understand what factors, besides the employees' health, the wellness programs can impact. Survey participants were self-identified employees of the hospitality organization who did or did not participate in the wellness program. Research findings indicated there was a significant difference in extrinsic and intrinsic job satisfaction levels between employees who participated and employees who were nonparticipating in the wellness program.

Design/methodology/approach - The population for this study was from a contract foodservice organization that provides facility services to higher education organizations, from their northeast regional location that consisted of approximately 200 employees. The employees of the organization ranged from entrylevel positions, up to and including senior-level management. The researcher solicited employees in all departments in the organization to participate in the survey. The company offers a comprehensive wellness program, and all employees in the organization had a choice to participate in the wellness program.

Findings - The intent of the study was to determine if participating in a wellness program affected the employee's job satisfaction levels. Securing a hospitality organization to survey was a challenge, possibly because the survey included questions about job satisfaction. The purpose of the study was to identify whether participation in the wellness program affected employees' extrinsic and intrinsic job satisfaction levels. Hospitality organizations continue to allocate resources to implement and improve existing wellness programs in the workplace. Researchers had not specifically focused on the potential impact a wellness program might have on employee job satisfaction levels. Cyboran and Goldsmith (2012) concluded organization leaders should take steps to create an effective workplace. The study showed that even though hospitality organization leaders are dedicating resources to the development and implementation of wellness programs, participating in the wellness program has an effect on increasing or maintaining current employees' extrinsic and intrinsic job satisfaction levels throughout the organization.
\end{abstract}

Originality/value - This is the author's research that was conducted for a dissertation that has been turned into a research article for publication.

Keywords Comprehensive, Wellness program, Extrinsic, Intrinsic, Job satisfaction, Participant,

Nonparticipant

Paper type Research paper

\section{Introduction}

Over the years, corporations have implemented wellness programs in the workplace that leaders feel can potentially reduce health care costs for the organization and the employees and can impact productivity, which has the potential to increase the organization's bottom line (Bard, 2011). Organizational leaders should determine proactive solutions to offset the employers' increasing cost in providing health care - one solution is providing integrated

(C) Craig Marshall. Published in International Hospitality Review. Published by Emerald Publishing Limited. This article is published under the Creative Commons Attribution (CC BY 4.0) licence. Anyone may reproduce, distribute, translate and create derivative works of this article (for both commercial and non-commercial purposes), subject to full attribution to the original publication and authors. The full terms of this licence may be seen at http://creativecommons.org/licences/by/4.0/legalcode

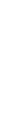


IHR

34,2

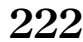

wellness programs that encourage total health and well-being (Izlar, 2011). Companies starting wellness programs realize there will be issues. Some of the issues include determining ways to encourage employee participation in the wellness program. This issue might be resolved by incentivizing participation and developing other options for the employees to take advantage of the wellness program. A major factor organizational leaders need to keep in the forefront is complying with legal and ethical considerations that are related to implementing a wellness program, some of which are as follows, Employee Retirement Security Act (ERISA), Patient Protection and Affordable Care Act (ACA), Health Insurance Portability and Accountability Act (HIPPA) and Americans with Disabilities Act (ADA).

Carlson and Murphy (2010) reported that 133 million Americans suffer from several types of chronic condition, including arthritis, asthma, depression, heart disease and diabetes, which is becoming one of the top diseases in the United States. The rise in health insurance costs prevented low-income workers from getting coverage, even if their employer offered a health insurance plan (Blakely, 2010). In 2012, employers across the United States were getting ready to implement the ACA at the beginning of 2014 (Wojcik, 2012). The basis of the ACA was to promote access to care and strengthen consumer protections (Fielding et al., 2012). In 2014, employers decided to assess whether their plans met ACA guidelines. Analysts at the Congressional Budget Office estimated the ACA would provide health insurance to 35 million additional individuals by 2021 (Berman, 2011). The ACA is a historic opportunity to reorient the US health care system with a focus on preventive care instead of a focus on illness and intervention. The ACA supports clinical medicine through employee health prevention that builds and strengthens the groundwork for prevention and wellness (Fielding et al., 2012).

Part of the implementation of the ACA is to assess penalties to organizations that do not meet several minimum requirements. The penalties are as follows: (1) $\$ 3,000$ annually per employee for whom coverage does not meet the federally subsidized coverage on state health plans, (2) $\$ 2,000$ annually for qualified full-time employees if the employer offers no workplace health coverage and (3) \$2,000 annually for each qualified full-time employee on the organization's payroll and not in a sponsored health plan, with certain exceptions (Berman, 2011). Many officials in the government and consumers familiar with the ACA question if employers will drop health coverage altogether, as the penalty is less than offering coverage to full-time employees. Madison et al. (2011) addressed three controversies associated with the implementation of the ACA. First, organizational leaders throughout the United States question the effectiveness of incentive programs improving health, regardless of the efforts of the organizations. Second, employees argue it is not appropriate for employers to take such an active stance in trying to improve or influence their personal health. Third, many people look at the financial incentive program as coercive or a potential tool for discrimination (Madison et al., 2011).

With the escalation of health care costs, leadership's engagement in assessing the health of employees increased. One part of the process involved improving the type of care delivered to the employees. According to Skrepnek et al. (2012), employers often focused on assessing short- or long-term disability, workers compensation, presenteeism and absenteeism, measurements related to productivity and employee turnover or replacement costs.

Organizational leaders attempt to evaluate the extent to which presenteeism costs contribute to the overall costs associated with health conditions. No standardization exists for an organization to implement an appropriate approach to measure presenteeism (Skrepnek et al., 2012). Three commonly used measurement strategies organizational leaders can implement are (1) self-initiated reports (e.g. wellness survey tools piggybacked with observed studies), (2) simulations (e.g. for employee productivity forecasting) and (3) a retrospective database (e.g. potential medical health claims with employee productivity data (Skrepnek et al., 2012). 
Organization leaders proactively try to find a solution to the rising health care costs using integrated wellness programs that emphasize employee awareness of their total health and well-being (Osilla et al., 2012). If firms are to remain competitive in the marketplace, wellness programs will become a best practice offered to employees and when recruiting top talent (Izlar, 2011). The rise in health care costs and wellness programs is going to become a benefit that firm leaders may assess as worthwhile to employees (Wojcik, 2012).

The purpose of this study was to examine a correlation between employees who participate/do not participate in a wellness program and their extrinsic and intrinsic job satisfaction levels. Organizational leaders originally implemented wellness programs as a way to improve employee wellness (Lee et al., 2010), but realized quickly the wellness programs might serve as a way to improve employee health and job satisfaction (Ickes and Sharma, 2009). An investment in employee health may lead to reduced absenteeism, improved job satisfaction and increased productivity (Lee et al., 2010).

\section{Literature review}

Wellness programs are becoming increasingly popular because researchers have demonstrated to US employers that these programs can potentially reduce health costs and increase productivity, which increases the bottom line of the business sponsoring them (Bard, 2011; Song and Baicker, 2019). Hospitality leaders need to focus on proactive solutions to increasing employer costs for health care by providing integrated wellness programs that emphasize total health and well-being (Izlar, 2011). The issues related to starting wellness programs include encouraging employees to participate in the programs by developing incentives and options for them to take advantage of the wellness programs. As organizational leaders implement wellness programs for employees, the leaders will need to keep abreast of the legal and ethical considerations related to implementing a wellness program.

\section{Defining wellness programs}

Wellness programs are not new, and it is also not a new strategy organizations are implementing to reduce health care costs. With health care costs continuing to increase on a yearly basis, leadership needs to focus on using wellness programs as an incentive to improve the health of employees and, in some instances, offer discounts on premiums based on participation in the wellness program. The early development of wellness programs and the focus of these early wellness programs included five dimensions and 16 skill areas, including personal responsibility, individual excellence, cultivating personal passion, refining critical thinking skills and lifelong quest to become or stay healthy (Ardell, 2011; Song and Baicker, 2019). The list also included humor, play, optimism, extraordinary levels of fitness and more. Ardell (2011) noted wellness is associated with the idea of freedom and democratic values that originated in Greece and was embodied into the US Constitution. In a broad sense, wellness stands for the values of a productive good life for each person (Ardell, 2011).

An active proponent of a spiritually based notion of wellness argued comprehensive wellness programs should serve as an opportunity for employees to improve their health and their total well-being (Ardell, 2011; Mayer, 2016). As a supporter of the broadest contraction of comprehensive wellness programs, Ardell (2011) repeatedly criticized the narrow focus of comprehensive programs on disease prevention management. Although most comprehensive wellness programs involve some aspect of health testing, smoking cessation and weight management, real comprehensive wellness programs need to focus on a person's total health and well-being. Some health officials continue to support the original broad-based wellness programs and continue to find a lot to criticize regarding the 
IHR

34,2 current manifestation of comprehensive wellness programs that most companies offer (Moran, 2013).

The comprehensive wellness paradigm led managers to consider using biomedical and anatomical metaphors to describe organizations in terms of total health. Organizational leaders continue to offer ways to make employees healthier by focusing on the persistence of negative features derived from outmoded capitalistic models. Analysis shows a split between ideas on how to implement comprehensive programs in organizations and how to keep the chaos of the implementation at bay. Establishing an exercise regimen can provide an opportunity to improve wellness in individuals, and exercise may tacitly create an opportunity to improve the lives of employees outside the workplace. There is a fine line between encouraging employees to exercise and controlling the employees, which could be construed as a reason why employees may choose not to participate in organizations' comprehensive wellness programs. Leadership's goal is to present the comprehensive wellness program in a fashion that employees will see a general culture focus to have fun and improve employees' health (Ardell, 2011; Moran, 2013).

Arguments continue against the idea that leaders of large organizations attempt to dictate employee health. With the recent potential rise and uncertainty of health insurance rates, employees may be more open to participating in organization-sponsored comprehensive wellness programs with the hope that participating will lead to healthier lifestyles and reduced health insurance costs. The potential remains that a consensus view may be in danger of becoming an untested myth, as employers continue to place demands on return on investment evaluations of comprehensive wellness programs to prove if such programs are worth the investment (Moran, 2013).

Employees might conclude that the benign reason or motivation behind comprehensive wellness programs is an attempt by organizational leaders to provide a way for employees to improve their health and well-being in which employees would show little opposition to participating in an organization's comprehensive wellness program. Comprehensive wellness programs might face resistance because they could be susceptible to violations of federal laws. The ACA provides guidelines and provisions about what constitutes a comprehensive wellness program. For example, leaders must adhere to HIPAA. The aim of HIPAA is to ensure patient confidentiality, which encompasses being forbidden to ask about hereditary conditions as a basis of discrimination. The motivation for seeking hereditary information on diseases such as cancer or Alzheimer's could be construed as an attempt to avoid extra health care costs associated with the risks of insulating individual employees (Ardell, 2011; Song and Baicker, 2019).

Comprehensive wellness programs include some type of interview process on employees' current health behaviors and history, and Ardell (2011) worried that employers might influence trusting employees to reveal too much information about their hereditary health traits that might lead to leaders not hiring or (dismissing) an employee. Concerns exist regarding offering cash incentives to participate in comprehensive wellness programs, as incentives might lead employees into divulging incriminating hereditary information. Because of confidentiality laws, managers are discouraged from guiding at-risk employees to needed diabetes, cardiac and respiratory prevention programs (Ardell, 2011).

\section{Comprehensive wellness programs}

Comprehensive wellness programs entail a preventative approach to disease management as opposed to a treatment approach. Originators of the movement for comprehensive wellness programs favor a broad design measurement of total wellness such that it is difficult to measure one aspect of a total comprehensive wellness program to determine potential impact (Clower, 2010; Harris, 2010; Slutzky, 2010; William and Tacker, 2010; Song and Baicker, 2019). 
According to Mayer (2016), wellness programs are evolving into comprehensive spiritual packages, no longer looking solely at behaviors, but analyzing the overall health. As part of the continuation of building the wellness programs, organizations are also including financial wellness. Money is a leading cause of stress which, in turn, impacts overall health. Adding financial wellness to the existing comprehensive wellness program provides the employee with a sense of tackling something, which can have a huge impact on their overall mental state (Mayer, 2016).

Comprehensive wellness strategies range from changing on-site cafeteria menus, removing vending machines or offering healthier vending machine choices and reduced pricing with the on-site cafeteria to promote healthy eating. For example, on-site cafés might include healthier food choices at reduced prices to encourage employees to choose the healthier option. Another avenue to promote wellness in the workplace is to encourage employees to participate in Weight Watchers through meetings located at either the workplace or locations around the community. Organizational leaders may even offer to subsidize the cost to join Weight Watchers to increase enrollment and provide another tool to make a wellness impact (William and Tacker, 2010). Another area in which corporate leaders attempt to increase wellness opportunities is replacing coffee breaks with wellness activities, such as yoga or other low-impact exercise programs (Bard, 2011). As comprehensive wellness programs continue to become popular, the leaders of more organizations are implementing health-risk assessments to measure participation in the corporate-sponsored wellness program; assessing health risk also provides an opportunity to measure results. Some organizations have in-house clinics or nurse practitioners to provide quick health assessments instead of going to the doctor's office just to get blood pressure tests (Grant, 2012).

Another aspect of a comprehensive wellness program is the use of health risk assessments (HRAs). HRAs are used by the organization to develop relevant and targeted employee health interventions. Conducting HRAs on employees provides the organization with a snapshot of the employees' overall health. By gathering these data, the leaders of the organization can determine which wellness programs might be better suited for the employee population in an attempt to improving employees' overall health. HRAs also provide employees with a picture in time of their overall health which can be tracked year over year (Howarth et al., 2017)

Corporations may, at times, have a focus that is too narrow to offer a comprehensive wellness program, which can be problematic. If the focus of a corporation becomes too narrow regarding what problems the program is trying to attempt to influence, the corporation leaders run the risk of failing to implement a successful comprehensive wellness program. Comprehensive wellness programs originally began as an effort by organizational leadership to help workers to be more satisfied in the workplace, to increase pressure to find ways to reduce health care costs and to cause organizational leaders to implement programs in a manner that might bring a return on investment. Organizational leaders are implementing comprehensive wellness programs to reduce the health care premiums they pay to provide health insurance benefits to employees (Grant, 2012).

\section{Examples of comprehensive wellness programs}

Most of the literature reviewed indicated comprehensive wellness programs show the potential to reduce health care costs, absenteeism and other indirect costs associated with employee turnover (Grant, 2012). An evaluation of the literature revealed this fact was true only when comprehensive wellness programs are well designed. Results favor programs that are more comprehensive, using the broadest spectrum associated with wellness to target the needs of individual employees, and realizing not one program fits all needs (Grant, 2012). 
IHR

34,2
The following studies evaluated comprehensive wellness programs used by organizations. The first survey was conducted by Kaiser Family Foundation (2014) researchers. The study took place in 2013 in partnership with Health Research and Education Trust (HRET), which is a private, nonprofit organization involved in research, education and demonstration programs that address health management and policy issues. Kaiser Family Foundation is the leader in health journalism, communication and health policy analysis. The $\mathrm{KFF} / \mathrm{HRET}$ survey contained information from 1999 through 2013, with specific results from 2013. The study was conducted via telephone and involved surveying 2,067 randomly selected public and private employers with three or more workers. The focus of the KFF/ HRET survey was to study the impact of having a wellness program in the organization. The survey did not ask or seek to determine if the wellness program affected the extrinsic and intrinsic job satisfaction levels of the employees participating in the wellness program (Kaiser Family Foundation, 2014).

PepsiCo leaders funded the next study, and researchers at the Rand Corporation conducted the study in 2014; during the survey, PepsiCo employed 67,000 individuals. The primary result for the study was the potential for a wellness program to lower health care costs for workers with chronic diseases, along with components of the wellness program to encourage employees to adopt healthier lifestyles. The study provided data over a seven-year period, but no data in the study provided information about whether having a wellness program affected employee job satisfaction. (Rand Corporation, 2014).

Leaders of a Chicago organization developed a workplace wellness program in 2008 and used professional nurses to oversee the program and to evaluate the results of the program by conducting a personal wellness profile for each employee (Carlson and Murphy, 2010). The researchers administered an HRA profile to the participants. The profile is a comprehensive HRA, which included an assessment of vital signs, some laboratory data and a health assessment. After all employees completed the HRA, the next step was to implement programs where employees could participate to determine if they could improve their personal health. After employees participated in the wellness programs for a specified length of time, they again completed the personal wellness profile. The nurses analyzed the data to see if employees were able to improve their personal health. The employees who participated in the wellness programs experienced personal health improvement by reducing their risk of heart disease, reducing their cholesterol and improving their fitness (Carlson and Murphy, 2010).

Jones et al. (2019) designed and implemented a comprehensive wellness program at a workplace in Illinois. The comprehensive wellness program was called iThrive; to help attract employees to participate, the program was incentivized. The program looked at average medical spending, gym visits, employee absenteeism, productivity, health behaviors, job satisfaction and self-reported health. This study concluded that participating in the wellness program did not have an impact on employee job satisfaction, but the study did not look at intrinsic and extrinsic satisfaction. The study only asked if the employees were satisfied with their job, happy at work, show an interest in presenteeism, feel productive at work or received a promotion. It asked the employees prior to enrolling in the program (pre-test) and after being in the program for 2 years (post-test). The outcome of this study showed only two statistically significant effects from the 42 outcomes the study examined. First, the study showed an increase in the number of employees that received a health screening. Second, there was an increase in the number of employees who felt management places a priority of health and safety (Jones et al., 2019). Only one year of iThrive results were examined which did not show significant effects for the outcomes examined. Jones et al. (2019) discussed the possibility that longer run effects may emerge in later years. Jones et al. (2019) reported wellness programs can vary by organizations, and other designs that include different employee populations to participate, by including biometric screenings, may provide different results from what was found with this study. 
Comprehensive wellness programs in the workplace will only be successful in reducing employer and employee health insurance costs if leaders increase or encourage participation in the programs. Participation in comprehensive wellness programs is a concern for any organization whose leaders are attempting to offer a comprehensive wellness program. Any attempt for organizational leadership to maximize participation will be difficult, as each organization will have different circumstances that factor into encouraging participation (Wojcik, 2012).

Wellness programs are becoming a key strategy in combating health risk factors and staying competitive, profitable and successfully attracting and retaining top talent (Wojcik, 2012). The question of whether comprehensive programs are beneficial requires further investigation regarding whether a financial benefit occurs for the parties involved in the comprehensive wellness programs (Wojcik, 2012). McLellan et al. (2009) showed a 23\% participation rate within organizations across the United States. Robroek et al. (2009) showed a similar participation rate ranging from ten to $64 \%$, but recorded an average rate of $33 \%$. Implementation of a comprehensive wellness program requires more financial and management resources.

\section{Health and safety}

The overall health of the population has slowly deteriorated, mainly because the US population embraced a culture that is less active and a diet that consists of mostly convenient unhealthy foods (Barkin et al., 2010). Researchers at the US Department of Health and Human Services (2011) estimated that approximately two-thirds of the US population is either obese or overweight, and $17.5 \%$ of children aged 11-18 are obese or overweight (US Department of Health, 2011). Klein and Simmers (2009) compared the fight against childhood obesity to the fight against smoking, and indicated it will become a social movement similar in proportion with a premise that people should consider obesity a threat much like smoking. A social and media war raged against the dangers of smoking, especially within the juvenile population. The war waged on smoking helped bring about social awareness and reduced smoking rates. An effort of similar magnitude may be essential to increasing the collective concern regarding the obesity pandemic (Klein and Simmers, 2009).

Gabel et al. (2009) showed that $77 \%$ of employees indicated they were somewhat concerned and $26 \%$ were particularly concerned about weight management. They also showed that $80 \%$ of the employees surveyed agreed that programs addressing weight management and promoting healthier lifestyle choices belong in the workplace. Organizational leadership who examine their employees and their employees' lifestyle choices based on health can be surprised at the results (Gabel et al., 2009). Obesity, which can lead to other serious health problems such as diabetes and cardiovascular disease, has significant financial implications. The nonprofit, nonpartisan group Trust for America's Health, whose primary goal is to improve health across the United States, reported that an average investment of $\$ 10$ per employee for obesity prevention could save the organization an estimated \$1 million over 5 years (Klein and Simmers, 2009). Researchers at the US Department of Health and Human Services (2011) gathered some data regarding obesity. Although most people believe that an individual becomes overweight by overeating, other variables also play a significant role in becoming obese. The variables include a person's genetic makeup, environmental influences and individual factors. Klein and Simmers (2009) posited there is no single cause for obesity, which means there is no one-size-fits-all solution to the current obesity problem in the United States. Treatment options vary, depending on the person and the situation, and range from something very straightforward such as dieting to a more drastic option such as surgery. One underlying theme common to all the treatment options is behavior modification. Most comprehensive wellness programs include behavior

\section{Wellness program's impact on job satisfaction}

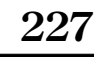


IHR

34,2

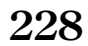

modification by teaching participants the importance of making healthier dietary choices or the effect of increasing daily exercise. Obesity is associated to health concerns such as stroke, hypertension, coronary heart disease, diabetes and cancer variations (US Department of Health and Human Services, 2011).

The overall health of the country and employees has a financial impact on everyone. For example, $75 \%$ of annual health care costs in the United States originate from health conditions that are preventable (Loeppke et al., 2010). They concluded that by decreasing the absenteeism rate for each employee by just one day per year, organizations would realize $\$ 18.8$ million in potential savings. If an organization's leadership wanted to achieve a similar financial benefit, they would need to increase sales by over $\$ 76$ million. Loeppke et al. (2010) discussed health risks and indicated many health risks among employees can be addressed quickly through comprehensive wellness programs. For example, people who are at higher risk for becoming diabetic, as indicated by high blood pressure, high blood sugar while fasting and high level of stress, can significantly reduce their risk for diabetes in 1 year by adopting healthier eating habits (Loeppke et al., 2010).

\section{Job satisfaction and wellness programs}

Like most other programs within organizations, job satisfaction motivates a comprehensive wellness program. Although leaders might have a genuine concern about their employees, they implement comprehensive wellness programs to curtail the rising health care costs placed on employers and employees. Organizational leaders believe there is a potential to lower their health care premiums by addressing the causes for premature death and diseases among the employee population. As the overall health of the United States continues to decline, costs associated to health care continue to rise; the ACA is an attempt by the US government to curtail rising health care costs. The costs associated with health care are becoming a considerable burden on businesses, as well as on job satisfaction rates (Yen et al., 2010).

Intrinsic and extrinsic job satisfaction is "a positive emotional state, which reflects a certain response to a job situation" (Wright, 2010, p. 28). As employees participate in wellness programs and experience potential physical changes, they develop a connection to selfesteem and enthusiasm (Wojcik, 2012). Evaluation of job satisfaction in the organization by offering a wellness program can be examined to see if the wellness program improves job satisfaction. A review of a wellness program from the standpoint of job satisfaction may demonstrate a clear relationship between wellness programs and job satisfaction (Wojcik, 2012).

In the corporate organizational setting, some research exists on job satisfaction and wellness programs, but there is little understanding about a correlation between wellness programs and job satisfaction (Wright, 2010; Jones et al., 2019). Job satisfaction is an area of interest for organizations offering wellness programs, which may provide leadership with another tool to enhance job satisfaction for their employees. Louden (2013) found a connection with job satisfaction and age such that older, more experienced employees typically express less job dissatisfaction. One reason for seasoned employees to feel less job dissatisfaction is an increased opportunity to embrace a wellness program fully and offer suggestions to leadership on how to improve the wellness program over time (Louden, 2013).

Wojcik (2012) and Louden (2013) indicated that a significant relationship existed between improved job satisfaction among employees who participated in a wellness program and employees who did not participate in a wellness program. Although the effect of improved job satisfaction is not the only contributor to participation in a wellness program, employees who exercised regularly on their own achieved a higher level of job satisfaction compared to those who did not exercise on their own. Access to an exercise facility helped create a supportive 
environment that may enhance employee health and therefore increase job satisfaction (Wright, 2010).

According to Wojcik (2012), the leaders of an organization called Event Network, Inc., focused on understanding employees and making sure employees felt satisfied in the workplace. Event Network leaders provided all new employees a gym bag with an exercise ball, a reusable culinary set and a water bottle. Event Network leaders recognized that happy employees are more productive employees. Leaders encouraged employees to get up from their cubical and move around during the day, as creativity increases when individuals change environments (Wojcik, 2012). Louden (2013) indicated that organizational leaders believe the impact generated by wellness programs contributed toward employees experiencing increased job satisfaction and lower turnover rates and absenteeism.

Organizational leaders often overlook public image when determining if they should implement a comprehensive wellness program, even though such a program could potentially impact job satisfaction. Such an organization will become an employer where others will want to work, which adds influence on the organization, although this is difficult to measure (Zwetsloot et al., 2010). With organization leadership providing benefits such as a fitness center, employees are more likely to inform friends about the benefit, which also aids in increasing job satisfaction. The leaders of such organizations can spend less money on recruiting new employees, as the reputation of the organizations in the community is desirable, and potential employees come to them (Zwetsloot et al., 2010).

According to Fielding et al. (2012), the US Preventive Service Task Force on Immunization recommends all insurance policies and group plans cover effective clinical prevention services at no cost to patients. Community health centers and the National Health Service Corps developed a partnership to strengthen the public health care infrastructure, and the ACA authorized this investment along with a host of other programs. The National Prevention Health Promotion and Public Health Council created by the ACA established a formula for a National Prevention Strategy. Finally, the Prevention and Public Health Fund, also enacted by the ACA, provided $\$ 16$ billion in new financing for expanding and sustaining the necessary infrastructure to detect early onset disease and prevent disease the next 10 years in cooperation with other provisions contained in the ACA to minimize health conditions before they become severe (Fielding et al., 2010).

The ACA offers support to decrease obesity in many ways. Leaders at the US Food and Drug Administration implemented new federal regulations on nutrition labeling for foods sold at certain retail food outlets and franchise restaurants (Fielding et al., 2010). Heart-related risks and obesity are becoming an enormous problem in the corporate workplace, and leaders in corporations are taking a reactive approach to this problem (Arena et al., 2013). In 2010, the leaders of an organization offered health care benefits totaling $\$ 3.7$ billion to provide nearly 900,000 retirees, employees and their family members with affordable high-quality coverage (Izlar, 2011).

To gauge the success of a wellness program, organizational leaders attempt to measure the potential increase in job satisfaction, which is a critical component of a wellness program. Beginning in 2014, the ACA will allow the use of 30\% of health insurance premiums for outcome-based wellness incentives (Arena et al., 2013). Business leaders will need to become proactive in providing a solution to the rising health care costs by using comprehensive wellness programs that emphasize employees becoming aware of their total health and wellbeing. If leaders wish their organizations to remain competitive in the marketplace, they will need to offer this practice to retain employees and to recruit top talent (Arena et al., 2013).

Offering a wellness program in a corporation will benefit the employees who volunteer for the program, and there is an opportunity for the organization to increase job satisfaction, which should increase revenue and profitability. The issue of starting a comprehensive wellness program is showing the employees the benefits of becoming healthier. Leaders of an organization

\section{Wellness program's impact on job satisfaction}

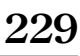


IHR

34,2

may need to develop incentive options to help drive the wellness programs that they develop. Another issue that organization leaders should keep in mind when developing a wellness program is the legal requirements that they need to address and follow (Arena et al., 2013).

As US organizations continue to move from a manufacturing workforce to a service workforce, the imbalance between output (physical activity) and energy intake (nutrition) has led to an increase of obesity and correlating diseases among employees (van Dongen $e t$ al., 2011). In addition to the toll that obesity takes on the health and well-being of employees, the other is decrease in job satisfaction in terms of lost productivity and health care costs among an organization's employee workforce. Research noted obesity-related medical payments account for approximately $6 \%$ of health insurance costs among US organizations with employer-provided health care insurance. With employee population becoming overweight and obese, the organization bears the monetary consequences for reduced job satisfaction. Employees who are overweight or obese collect paychecks and, in most circumstances, receive employer-based health insurance (van Dongen et al., 2011).

The empirical framework for this study was to determine if there was any impact on job satisfaction when offering a comprehensive wellness program. According to Lee et al. (2010), investing in employee health may lead to reduced absenteeism, improved job satisfaction, and increased productivity. The literature review for this quantitative research study addressed many aspects of wellness programs in organizations. While examining the relationship of a wellness program in an organization, little evidence emerged to show wellness programs influencing extrinsic and intrinsic job satisfaction levels of employees who participate in a wellness program. Literature gaps and a lack of scholarly research revealed no primary data on extrinsic and intrinsic job satisfaction levels for employees participating in wellness program.

According to Ghauri and Gronhaug (2010), secondary data are not comparable to primary data, as primary data avoid interpretation through the eyes of another interested party. This study involved examining primary data from respondents in an organization that has a wellness program. The research attempted to provide insight that adds to the current body of knowledge on wellness programs and the impact on the organization.

Avia (2010) conducted a survey for a health insurance company located in the United Kingdom in July 2011 with 2,000 employees across a wide range of businesses. The survey results indicated that business leaders were starting to realize that the health of their employees could potentially affect organizations' bottom line through a loss of productivity, with $42 \%$ of the employers surveyed recognizing the direct relationship between employees' health and organizational productivity (Avia, 2010). The percentage of employers who believed a healthy employee is more productive increased by $10 \%$ from the previous year's survey, with $63 \%$ believing this is true. In addition, $61 \%$ of the employees in the survey indicated that when an employer invests in their health and well-being, they will work harder for the employer, resulting in increased productivity (Avia, 2010).

\section{Methodology \\ Instrument/measures}

According to Dhammika et al. (2012), the Minnesota Satisfaction Questionnaire (MSQ) is a valuable tool researchers have used over many years and in many contexts for research on job satisfaction. Buitendach and Rothmann (2009) used the MSQ to study job satisfaction in an organization between two groups of employees. By using the MSQ, the authors were able to obtain necessary data to compare job satisfaction levels. According to Martins and Procenca (2012), the MSQ is widely used in research and is stable over time. The instrument yields excellent data for analysis purposes when used in conjunction with job satisfaction (Martins and Procenca, 2012). 
Weiss et al. (1967) created the MSQ as an instrument to evaluate job satisfaction among employees. The researcher obtained written permission from a representative at the Vocational Psychology Research Department at the University of Minnesota. The current research study included employees who participated and employees who did not participate in the wellness program to determine if participating in the wellness program affects intrinsic and extrinsic job satisfaction. The MSQ is a two-part survey. The first part provided intrinsic and extrinsic job satisfaction information, and the second part provided demographic information and a question asking the employee if they participated in the wellness program. Because the MSQ provides questions pertaining to intrinsic and extrinsic job satisfaction, this is the primary reason this survey instrument was utilized (Martins and Procenca, 2012).

The MSQ instrument has 20 psychology-based questions seeking job satisfaction levels. This research used the $1967 \mathrm{MSQ}$ format which has a five-point scale. The questionnaire has a Likert-type scale that ranges from (1) very dissatisfied to (5) very satisfied. A Likert-type scale ensured adequate sensitivity to measure the variability of the employees' responses. Administration of the survey in this questionnaire format provided the data needed to calculate the sample's characteristics, such as means, confidence intervals, standard deviations and averages. The demographic information gathered on the participants who took the survey was gender, age and tenure. See Figures 1-3 for demographic information.

The Job Satisfaction Survey (JSS) was considered as another instrument that could be used for this research. The JSS contains 36 items, with a nine-facet scale to assess employee attitudes and their job and aspects of the job. Each of the nine facts is assessed with four items, and a total score is computed from all items. The survey uses a summative rating scale, asking the participant to choose from one of the six choices, ranging from "strongly disagree" to "strongly agree." The nine facts cover the following areas: pay, promotion, supervision, fringe benefits, contingent rewards (performance-based rewards), operating procedures (required rules and procedures), coworkers, nature of work and communication (Spector, 1985).

Even though the JSS looks at job satisfaction, the researcher felt the MSQ was a better fit because it specifically has the questions broken down between intrinsic and extrinsic values, which was the basis for this research. According to Spector (1985), the JSS was also developed to cover major aspects of job satisfaction, which could help with future research as it pertains to job satisfaction and wellness program participation. Again, the primary purpose of using the MSQ was for its specific reference to intrinsic and extrinsic job satisfaction levels of employees.

\section{Data collection}

The population for this study was from a contract foodservice organization that provides facility services to higher education organizations, from their northeast regional location that

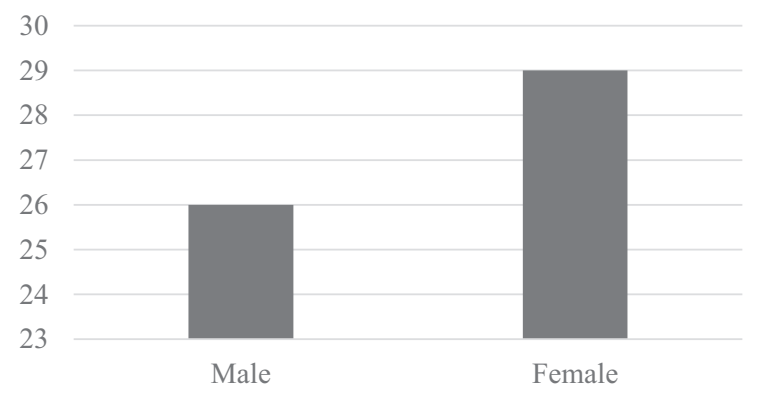

Figure 1. Gender of survey respondents

Wellness

impact on job

satisfaction

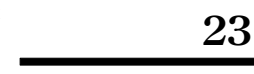


IHR

34,2

\section{2}

Figure 2.

Respondents' age range consisted of approximately 200 employees. The employees of the organization ranged from entry-level positions, up to and including senior-level management. The researcher solicited employees in all departments in the organization to participate in the survey. One additional follow-up email was sent three weeks after the initial email invite to participate in the survey. The company offers a comprehensive wellness program, and all employees in the organization had a choice to participate in the wellness program.

According to Faul et al. (2007), with four predictors (age, gender, tenure and participation in the wellness program), a medium effect size $\left(f^{2}=0.15\right)$ and an alpha of 0.05 , the sample size needed to achieve sufficient power $(0.80)$ was 85 . The basis of the sample frame for this study was a January 2014 study conducted by researchers at the Rand Corporation, which released the results of a study on PepsiCo, in which they surveyed all 67,000 employees. The company is a smaller organization, and all employees received a request to participate in the study. The entire population of the company had an opportunity to participate in the study. The researcher did not know how many employees did or did not participate in the wellness program. Segmenting the employees for solicitation did not matter, as the human resources personnel emailed all employees the link to a Survey Monkey questionnaire.

\section{Design}

This nonexperimental quantitative study examined primary data derived from responses from the MSQ questionnaire between job satisfaction and participating in a comprehensive wellness program. The results may provide a better understanding about wellness programs affecting job satisfaction. The research design will test the difference between intrinsic and extrinsic job satisfaction levels of nonparticipating employees and participating employees of a wellness program, thus providing organizations with evidence showing employees who participate in a wellness program have a higher level of job satisfaction.

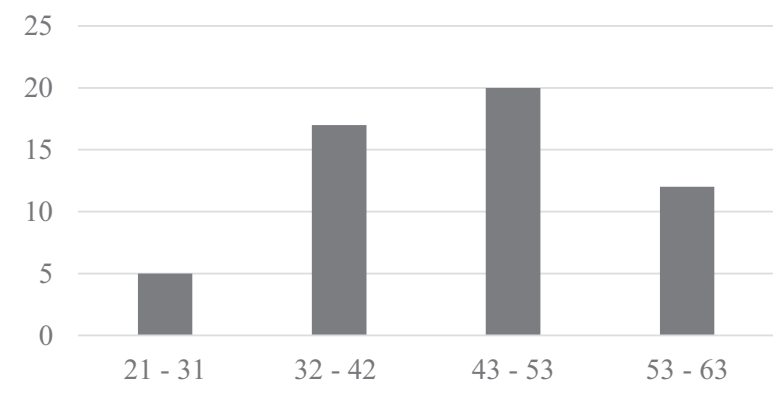

Figure 3.

Respondents' tenure with the company

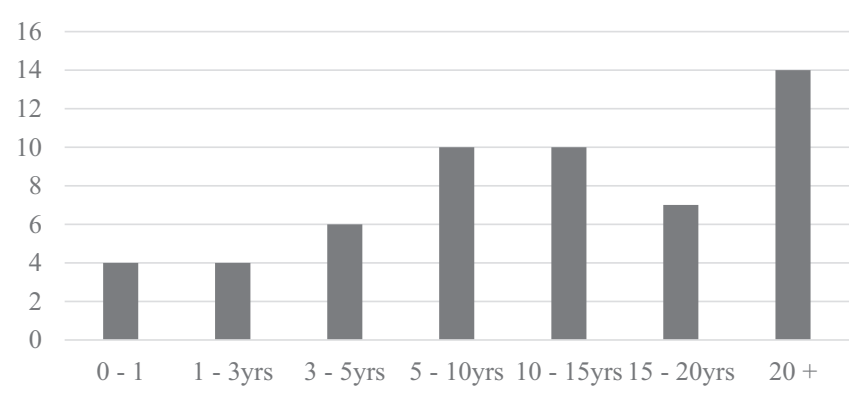


The research consisted of descriptive analysis utilizing the Mann-Whitney $U$ Test. This analysis is used to test the differences between two independent groups that are on a continuous measure. The two independent groups for this study are survey subjects that participate in the wellness program and survey subjects that do not participate in the wellness program. The Mann-Whitney $U$ test is the nonparametric alternative to the $t$-test for independent samples. Instead of comparing the means of the two groups, the Mann-Whitney $U$ test compares the median of the two groups. The Mann-Whitney $U$ test was selected because of the different group size; it compares the median of the two groups. The test converts the scores on a continuous variable to rank across the two groups, even though the two groups were a different size, because one group participated in the wellness program and the other group did not participate in the wellness program. The test then evaluates whether the ranks for the two groups differ significantly (Mann and Whitney, 1947).

\section{Data analysis}

The research examined comprehensive wellness programs and the impact of the programs on extrinsic and intrinsic job satisfaction levels. A Mann-Whitney $U$ analysis provided the basis to analyze and determine if a significant difference existed in the job satisfaction levels between participants and nonparticipants in the wellness program offered by the organization. The identified dependent variables were extrinsic job satisfaction and intrinsic job satisfaction and the independent variables were participation and nonparticipation in the wellness program.

\section{Results}

The participating group mean ranged from 1.56 to 2.69 , standard deviation ranged from 0.672 to 1.167 , median ranged from 1.00 to 3.00. The nonparticipating group mean ranged from 3.43 to 4.70 , standard deviation ranged from 0.703 to 1.201 , median range was from 4.00 to 5.00 . The total mean for participating/nonparticipating ranged from 2.67 to 3.15 , standard deviation ranged from 1.12 to 1.71 and medial ranged from 2.00 to 3.00. The participating group (group 1) was $N=23$, nonparticipating group (group 2) was $N=32$, total subjects for both groups was Total $N=55$. See Table 3 .

The sample size for the study was larger than 30, which resulted in the Mann-Whitney $U$ analysis providing the value for $\mathrm{a} z$ approximation, which includes a correction for ties in the data. The extrinsic independent variable $z$ value range was -4.874 to -6.455 and the significant value of $p<0.001$ on the following extrinsic questions: $1,2,3,4,7,8,9,10,11,15,16$, 17 and 20 . There is a statistical significant difference in extrinsic job satisfaction between the participating and nonparticipating groups in a wellness program; see Table 1.

The intrinsic independent variable $z$ value range was -1.838 to -5.571 and the significant value of $p<0.001$ on the intrinsic questions: $5,6,12,14,18$ and 19 . Only one question was slightly over the alpha level of 0.05 . Intrinsic question 13 had a significant value of $p 0.066$. There is a statistically significant difference in intrinsic job satisfaction between the participating and nonparticipating groups in a wellness program; see Table 2.

The statistical significance of this research shows that participating in a wellness program increases employees' extrinsic and intrinsic job satisfaction levels. Research has shown employees with a higher level of job satisfaction are more productive and less likely to seek out other employment opportunities. Organizations can use the wellness program as a recruiting tool in order to attract top talent.

\section{Discussion}

The intent of the study was to determine if participating in a wellness program affected the employee's job satisfaction levels. Securing a hospitality organization to survey was a

\section{Wellness \\ program's \\ impact on job \\ satisfaction}

233 
IHR
34,2

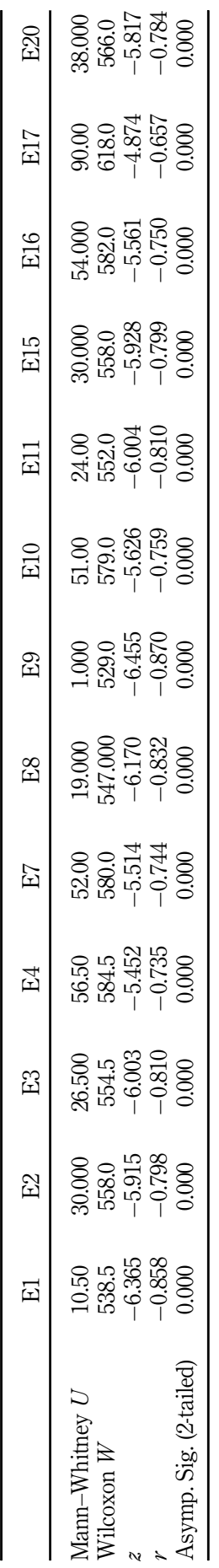

Table 1.

Extrinsic questions participating and nonparticipating group 
challenge, possibly because the survey included questions about job satisfaction. The purpose of the study was to identify if participation in the wellness program affected employees' extrinsic and intrinsic job satisfaction levels. Hospitality organizations continue to allocate resources to implement and improve existing wellness programs in the workplace. Researchers had not specifically focused on the potential impact a wellness program might have on employee job satisfaction levels. Cyboran and Goldsmith (2012) concluded organization leaders should take steps to create an effective workplace. The study showed that even though hospitality organization leaders are dedicating resources to the development and implementation of wellness programs, participating in the wellness program has an effect on increasing or maintaining current employees' extrinsic and intrinsic job satisfaction levels throughout the organization.

When thinking about overall job satisfaction in the workplace, extrinsic and intrinsic job satisfaction combined is what overall job satisfaction is in the workplace. Intrinsic job satisfaction is the actual work you do on daily basis. Extrinsic job satisfaction is what an employee considers about their working conditions, such as pay, coworkers, the environment in the office building and their managers. Research shows staying healthy increases a person's overall mindset which plays a factor in employees overall job satisfaction. Having a wellness program is going to impact the employee's thoughts about the working conditions and the office environment, since many wellness programs provide some type of access to a fitness center. The research specifically looked at extrinsic and intrinsic job satisfaction levels and shows participating in a wellness program impacts an employee's extrinsic and intrinsic job satisfaction levels.

\section{Theoretical implication}

The analysis showed that offering a wellness program and having employees participate in the wellness program influence extrinsic and intrinsic job satisfaction levels. Leaders should be actively looking for ways to improve employee satisfaction. There are two principal reasons leaders strive to improve employee satisfaction. First, as unemployment rates continue to fall, employees have the advantage in the workplace because employees are in demand. When unemployment is high, employers have more choices when considering employees for their open positions. High employee satisfaction shows potential and current employees that the organization is a pleasing place to work, which will aid in attracting top talent and can contribute to the organization's continued success. Based on the finding in this research, offering a wellness program is another way leaders in an organization can impact employee job satisfaction.

The workforce is becoming older and more dynamic. As the workforce ages, the demand for health care increases. In addition, the number of millennials and Gen $Z$ comprising the workforce is increasing. The millennials want a more flexible workplace and want to experience a higher level of job satisfaction based on the work they perform. Whereas Gen $Z$ are being categorized as being more like baby boomers looking to secure quality benefits along with workplace flexibility (Rolles, 2018). The results of this research provide evidence

\begin{tabular}{|c|c|c|c|c|c|c|c|c|}
\hline & I5 & I6 & $\mathrm{I} 12$ & $\mathrm{I} 13$ & I14 & $\mathrm{I} 18$ & I19 & \\
\hline Mann-Whitney $U$ & 106.500 & 50.000 & 163.000 & 264.500 & 170.000 & 91.500 & 160.000 & \\
\hline Wilcoxon $W$ & 634.500 & 578.000 & 691.000 & 792.500 & 698.000 & 619.500 & 688.000 & Table 2. \\
\hline$z$ & -4.554 & -5.571 & -3.616 & -1.838 & -3.481 & -4.876 & -3.656 & Intrinsic questions \\
\hline$r$ & -0.614 & -0.751 & -0.488 & -0.248 & -0.469 & -0.657 & -0.493 & participating and \\
\hline Asymptotic significance & 0.000 & 0.000 & 0.000 & 0.066 & 0.001 & 0.000 & 0.000 & nonparticipating group \\
\hline
\end{tabular}

Wellness program's impact on job satisfaction

235 
IHR

34,2

236

\begin{tabular}{|c|c|}
\hline 오 & \\
\hline$\stackrel{g}{g}$ & 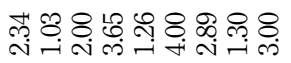 \\
\hline$\stackrel{\infty}{=}$ & 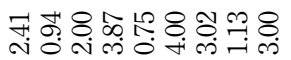 \\
\hline 武 & 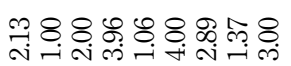 \\
\hline $\begin{array}{l}0 \\
\text { I }\end{array}$ & 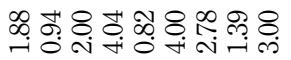 \\
\hline$\stackrel{1 \Omega}{19}$ & 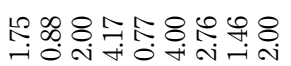 \\
\hline$\overleftrightarrow{\Xi}$ & F઼ \\
\hline$\stackrel{m}{g}$ & \\
\hline $\mathscr{\exists}$ & 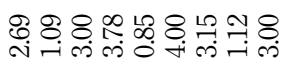 \\
\hline ت्ञ & $\begin{array}{l}\infty \\
\infty \\
\infty \\
\infty\end{array}$ \\
\hline 온 & 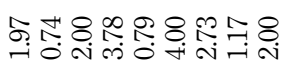 \\
\hline 오 & 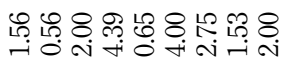 \\
\hline 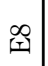 & ن. \\
\hline 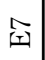 & 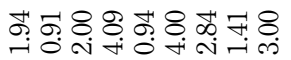 \\
\hline 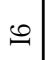 & 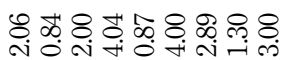 \\
\hline صـا & \\
\hline 枯 & 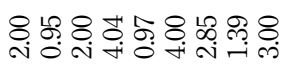 \\
\hline PI & \\
\hline 於 & హ. \\
\hline 도 & 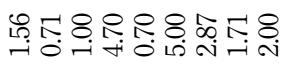 \\
\hline & 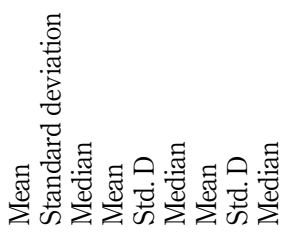 \\
\hline 夠 & $-\quad$ i. \\
\hline
\end{tabular}

Table 3.

Extrinsic and intrinsic participating/

nonparticipating group

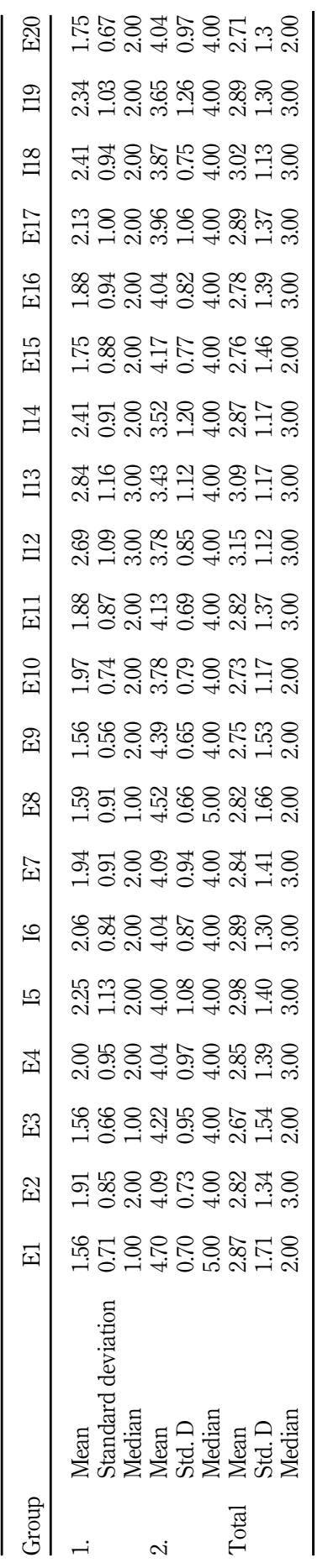


that participating in a wellness program will increase an employee's extrinsic and intrinsic job satisfaction levels. Organizational leaders should not only use a wellness program as a tool to improve employee health but also as a tool to improve employee job satisfaction levels.

\section{Managerial implication}

The specific problem that hospitality organizations face is the rising cost of health insurance and at the same time trying to improve job satisfaction in the workplace to maintain and attract top talent. This study involved quantitatively examining the relationship between extrinsic and intrinsic job satisfaction levels and participating in a wellness program to analyze the following research question: To what extent does a wellness program affect extrinsic and intrinsic job satisfaction?

As discussed, the analysis concluded that participating in a wellness program significantly improves an employee's extrinsic and intrinsic job satisfaction levels. This study shows that organizational leaders should continue to dedicate resources to their current wellness programs. Those organizations that do not offer a wellness program may want to think about ways to implement a wellness program or enhance the program that is in existence if leaders feel it is not robust enough. Specific action an organization could take is conduct a survey of their employees to determine what aspects of a wellness program they would like to see implemented. Reach out to similar-sized organizations and review their wellness program to see what they are providing. If the organization does not offer any type of wellness program, first action would be to survey employees to gauge their interest, reach out to their health insurance provider to see what they can offer in assistance in starting a wellness program and reach out to consultants that assist organizations in creating and implementing wellness programs in the workplace.

As organizations continue to offer or enhance their wellness programs, attention should be paid to incentives to encourage employee participation. Having a highly engaged workforce participating in the wellness can impact the employees' overall health costs but also improve their overall job satisfaction working for the organization. As discussed previously, if employees can improve their overall health by losing weight, this can contribute to improving unhealthy elements such as diabetes, high blood pressure and high cholesterol. This study has shown participating in the organization's wellness program can improve employee job satisfaction overall.

\section{Conclusion}

Use of the MSQ did indicate participating in a wellness program has an influence on extrinsic and intrinsic job satisfaction. The data collected from the survey respondents showed a statistically significant difference when comparing the extrinsic and intrinsic job satisfaction levels of employees who did and did not participate in the wellness program; see Table 3. Prior and current research findings supported other benefits for the implementation of a wellness program. The research and results show offering and implementing a wellness program not only can improve an employee's health, it can also inadvertently influence employees' extrinsic and intrinsic job satisfaction levels within the organization.

The leaders of the organization in this study offered a wellness program for employees, but the amount of emphasis leaders placed on participating in the wellness program remained unknown. Analysis of the research showed many organizational leaders are implementing wellness programs to improve employees' health, and not primarily to influence employees' extrinsic and intrinsic job satisfaction. As the status of health care coverage continues to be a volatile topic in the USA, organizations will continue to look for

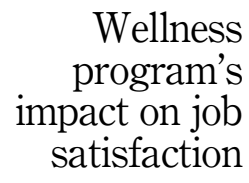


IHR

34,2

\section{8}

ways to enhance or improve existing employee health benefits. The study provided new information to organizational leaders on how to implement a wellness program successfully and how to encourage employees to participate in the organization's wellness programs. The findings of this research support the concept of implementing or enhancing a wellness program in the workplace, and as a side effect, it provides the organization with a means to enhance employees extrinsic and intrinsic job satisfaction levels.

\section{Limitations}

This study was limited to a hospitality organization that had a wellness program, and the study was not based on the specific type of hospitality organization or industry. The organization offered a wellness program, but it was not known how much emphasis was placed on participating in the organization's wellness program. Other organizations that had a known emphasis on participating in the wellness program were considered, but leaders of the organizations did not provide permission to conduct the survey.

Conducting the survey in a hospitality organization whose leaders emphasize the wellness program and surveying more participants may provide better insight on how much a wellness program influences employees' extrinsic and intrinsic job satisfaction. Organizations have different levels of wellness programs. Some organizations have a program focused only on weight loss, whereas other organizations have a wellness program focused on the overall health of the employees, including their financial and emotional health.

\section{References}

Ardell, D.B. (2011), "Building wellness models", Journal of the American Medical Athletic Association, Vol. 24 No. 3, p. 9.

Arena, R., Guazzi, M., BriggsPaige, D., Cahalin, L.P., Meyers, J., Kaminsky, L.A. and Lavie, C.J. (2013), "Promoting health and wellness in the workplace: a unique opportunity to establish primary and extended secondary cardiovascular risk reduction programs", Mayo Clinic Proceedings, Vol. 88 No. 6, pp. 605-617.

Avia (2010), "The fifth Avia health of the workplace report", available at: http://www.avaia.co.uk.

Bard, J.S. (2011), "When public health and genetic privacy collide: positive and normative theories explaining how ACA's expansion of corporate wellness programs conflicts with GINA's privacy rules", Journal of Law, Medicine and Ethics, Vol. 39 No. 3, pp. 469-487, doi: 10.1111/j. 1748-720X.2011.00615.x.

Barkin, S.L., Heerman, W.J., Warren, M.D. and Rennoff, C. (2010), "Millennials and the world of work: the impact of obesity on health and productivity", Journal of Business and Psychology, Vol. 25 No. 2, pp. 239-245, doi: 10.1007/s10869-010-9166-5.

Berman, M.L. (2011), "From health care reform to public health reform", Journal of Law, Medicine and Ethics, Vol. 39 No. 3, pp. 328-339, doi: 10.1111/j.1748-720X.2011.00603.

Blakely, S. (2010), "Employers, workers, and the future of employment-based health benefits", EBRI Issue Brief, Vol. 339 February, pp. 3-23.

Buitendach, J.H. and Rothman, S. (2009), "The validation of the Minnesota job satisfaction questionnaire in selected organizations in South Africa", South African Journal of Human Resources Management, Vol. 7 No. 1, pp. 1-8, doi: 10.4102/sajhrm.v7i1.183.

Carlson, E. and Murphy, M. (2010), "Impacting health through on-the-job counseling: role for professional nurses", Medsurg Nursing, Vol. 19 No. 5, pp. 295-299.

Clower, W. (2010), “The PATH wellness program”, available at: http://www.willclower.com/media/ SalesKit.pdf. 
Cyboran, S.F. and Goldsmith, C. (2012), "Making the case: new study shows it does, indeed, pay to become a healthy enterprise", Benefits Quarterly, Vol. 28 No. 1, pp. 26-37.

Dhammika, K.A.S., Ahmad, F.B. and Sam, T.L. (2012), "Job satisfaction, commitment and performance: testing the goodness of measures of three employee outcomes", South Asian Journal of Management, Vol. 19 No. 2, p. 7.

Faul, F., Erdfelder, E., Lang, A.G. and Buchner, A. (2007), "GPower 3: a flexible statistical power analysis program for the social, behavioral, and biomedical sciences", Behavior Research Methods, Vol. 39 No. 2, pp. 175-194, available at: http://www.gpower.hhu.de/.

Fielding, J.E., Teutsch, S. and Koh, H. (2012), "Health reform and healthy people initiative", American Journal of Public Health, Vol. 102 No. 1, pp. 30-33, doi: 10.2105/AJPH.2011.300312.

Gabel, J.R., Whitmore, H., Pickreign, J., Ferguson, C.C., Jain, A. and Scherer, H. (2009), "Obesity and the workplace: current programs and attitudes among employers and employees", Health Affairs, Vol. 28 No. 1, pp. 46-56, doi: 10.1377/hlthaff.28.1.46.

Ghauri, P. and Gronhaug, K. (2010), Research Methods in Business Studies, 4th ed., Pearson Education, Harlow.

Grant, E.M. (2012), “A case study evaluation of two corporate employee participation wellness programs: the Cessna comprehensive wellness program compared to the Kautex noncomprehensive program (Order No. 3502910)", Proquest Dissertations and Theses Global/ (993145964), available at: http://search.proquest.com.library.capella.edu./docview/993145964? accountid $=27965$.

Harris, B. (2010), "Employee maintenance: an effective safety and wellness strategy", Professional Safety, Vol. 10 No. 7 February, pp. 54-56.

Howarth, A., Quesada, J. and Mills, P.R. (2017), "A global, cross cultural study examining the relationship between employee health risk status and work performance metrics", Annals of Occupational and Environmental Medicine, Vol. 29 No. 1, doi: 10.1186/s40557-017-0172-1.

Ickes, M. and Sharma, M. (2009), "Worksite health promotion: a practical strategy for obesity prevention", American Journal of Health Studies, Vol. 24 No. 3, pp. 343-352.

Izlar, A.C. (2011), "The corporate role in reducing disparities: initiatives under way at Verizon", Health Affairs, Vol. 10 No. 1, pp. 1992-1996, doi: 10.1377/hlthaff.2011.0684.

Jones, D., Molitor, D. and Reif, J. (2019), "What do workplace wellness programs do? Evidence from the Illinois workplace wellness study, november 2019", The Quarterly Journal of Economics, Vol. 134 No. 4, pp. 1747-1791, doi: 10.1093/qje/qjz023.

Kaiser Family Foundation (2014), "Employer health benefits 2014 annual survey: worker and employer contributions for premiums", Medical Benefits, 2014, October 30, Vol. 31 No. 20, p. 4+.

Klein, M.J. and Simmers, C.S. (2009), "Exergaming: virtual inspiration, real perspiration", Young Consumers, Vol. 10 No. 1, pp. 34-45, doi: 10.1108/17473610910940774.

Lee, S., Blake, H. and Lloyd, S. (2010), "The price is right: making workplace wellness financially sustainable", International Journal of Workplace Health Management, Vol. 3 No. 1, pp. 58-69, doi: 10.1108/17538351011031948.

Loeppke, R., Edington, D.W. and Beg, S. (2010), "Impact of the prevention plan on employee health risk reduction", Population Health Management, Vol. 13 No. 5, pp. 275-284, doi: 10.1809/pop. 2010.0027e.

Louden, K. (2013), “Happiness and satisfaction”, Collector, Vol. 78 No. 7, pp. 29-30.

Madison, K.M., Volpp, K.G. and Halpren, S.D. (2011), "The law, policy, and ethics of employers' use of financial incentives to improve health", Journal of Law, Medicine and Ethics, Vol. 39 No. 3, pp. 450-468, doi: 10.1111/j.1748-720x.2011.00614.

Mann, B. and Whitney, R. (1947), "On a test of whether one of two random variables is stochastically larger than the other", Annals of Mathematical Statistics, Vol. 18 No. 1, pp. 50-60, doi: 10.1214/ aoms/1177730491. 
IHR

34,2

Martins, H. and Procenca, T. (2012), Minnesota Satisfaction Questionnaire - Psychometric Properties and Validation in a Population of Portuguese Hospital Workers (FEP Working Paper), Universidade do Porto, Porto.

Mayer, K. (2016), "Wellness programs evolving into comprehensive package: wellness programs evolving into comprehensive package", Employee Benefit News (Online), 2016, June 07, available at: https://search.proquest.com/docview/1911931644?accountid=10639.

McLellan, R., Mac Kenzie, T., Tilton, P., Dietrich, A., Comi, R. and Feng, Y. (2009), "Impact of workplace sociocultural attributes on participation in health assessments", Journal of Occupational and Environmental Medicine, Vol. 51 No. 7, pp. 797-803, doi: 10.1097/JOM. 0b013e3181a4b9e.

Moran, A.E. (2013), "Wellness programs after the affordable care act", Employee Relations Journal, Vol. 39 No. 2, pp. 75-83.

Osilla, C.K., Van Busum, K., Schnyer, C., Larkin, W.J., Eibner, C. and Mattke, S. (2012), "Systematic review of the impact of worksite wellness programs", American Jounral of Managed Care, Vol. 18 No. 2, pp. e68-e81.

Rand Corporation (2014), "Workplace wellness programs can cut chronic illness costs; savings for lifestyle improvements are smaller", Targeted News Service, 2014, January 06, available at: https://search.proquest.com/docview/1474502197?accountid=10639.

Robroek, S., van Lenthe, F., van Empelen, P. and Burdorf, A. (2009), "Determinants of participation in worksite health promotions programmes: a systematic review", International Journal of Behavioral Nutritional and Physical Activity, Vol. 6 No. 26, pp. 26-30.

Rolles, J. (2018), "Seeing past the generational stereotypes", Sdm, Vol. 48 No. 9, pp. 80-81, available at: https://search.proquest.com/docview/2114230653?accountid=10639.

Skrepnek, G.H., Nevins, R. and Sullivan, S. (2012), "An assessment of health and work productivity measurement in employer settings", Pharmaceuticals Policy and Law, Vol. 14 No. 1, pp. 37-49.

Slutzky, S. (2010), "Wellness programs catch on, but do they deliver?", available at: http:// thevitalitygroup.com/Bylines_and_op_ed/Wellness.pdf.

Song, Z. and Baicker, K. (2019), "Effect of a workplace wellness program on employee health and economic outcomes: a randomized clinical trial”, JAMA: The Journal of the American Medical Association, Vol. 321 No. 15, pp. 1491-1501, doi: 10.1001/jama.2019.3307.

Spector, P.E. (1985), "Measurement of human service staff satisfaction: development of the job satisfaction survey", American Journal of Community Psychology, Vol. 13 No. 6, p. 693, available at: https://search.proquest.com/docview/1295894482?accountid=10639.

U.S. Department of Health and Human Services (2011), Overweight and Obesity Statistics, available at: http://win.niddk.nih.gov/statistics/index.html.

van Dongen, J.M., Proper, K.I., van Wier, M.F., van der Beek, A.J., Bongers, P.M., van Mechelen, W. and van Tudler, M.W. (2011), "Systematic review on the financial return of worksite health promotion programmes aimed at improving nutrition and/or increasing physical activity", Obesity Reviews, Vol. 12 No. 12, pp. 1031-1049, doi: 10.1111/j.1467.789X.2011.00925.

Weiss, D., Davis, R., England, G. and Lofquist, L. (1967), Manual for the Minnesota Satisfaction Questionnaire. MPLS, University of Minnesota, Minneapolis, MN.

William, C.S. and Tacker, L. (2010), "The power of integrating consumerism and wellness", Benefits Quarterly, Vol. 26 No. 1, pp. 7-11.

Wojcik, J. (2012), "Health, happiness, job satisfaction”, Business Insurance, Vol. 46 No. 21, p. 12.

Wright, D. (2010), “A healthy workforce is good for business", Employee Benefits, Vol. 28 No. 20, p. 1.

Yen, L., Schultz, A.B., Schaefer, C., Bloomberg, S. and Edington, D.W. (2010), "Long term return on investment of an employee health enhancement program at a Midwest utility company from 1999 to 2007", International Journal of Workplace Health Management, Vol. 3 No. 2, pp. 79-96, doi: $10.1108 / 17538351011054998$. 
Zwetsloot, G.I.J.M., van Schppingen, A.R., Dijkman, A.J., Heinrich, J. and den Beston, H. (2010), “The organizational benefits of investing in workplace health", International Journal of Workplace Health Management, Vol. 3 No. 2, pp. 143-159.

Wellness program's impact on job

satisfaction

\section{Corresponding author}

Craig Marshall can be contacted at: marshallcr16@ecu.edu

For instructions on how to order reprints of this article, please visit our website: www.emeraldgrouppublishing.com/licensing/reprints.htm Or contact us for further details: permissions@emeraldinsight.com 